\title{
МЕТАФОРИЧЕСКОЕ МОДЕЛИРОВАНИЕ В ДИСКУРСЕ СМИ (НА МАТЕРИАЛЕ СТАТЕЙ, ПОСВЯЩЕННЫХ ВЫХОДУ ВЕЛИКОБРИТАНИИ ИЗ ЕС В БРИТАНСКОЙ, НЕМЕЦКОЙ И РОССИЙСКОЙ ПРЕССЕ)
}

\section{METAPHIRICAL MODELING IN MASS MEDIA DISCOURSE (BASED ON ARTICLES DEDICATED TO THE WITHDRAWAL OF THE UNITIED KINGDOM FROM THE EUROPEAN UNION IN BRITISH, GERMAN AND RUSSIAN PRINT MEDIA)}

M. Kurts L. Bykova

Summary: This article studies peculiarities of metaphorical modeling of the "Brexit" concept in British, German and Russian political discourse. The study is based on articles from the British, German and Russian media that use metaphors in order to describe the withdrawal of the United Kingdom from the European Union. The objectives of the study are to identify the most frequent metaphorical models, to conduct a detailed analysis of the examples, and to make conclusions regarding the general nature of each metaphorical model.

Keywords: Brexit, mass media, metaphor, metaphorical model, concept, connotation.

\author{
Кури Максим Андреевич \\ Сургутский государственный университет \\ kurtsmax@mail.ru \\ Быкова Людмила Владимировна \\ К.рилол.н., дочент, Сургутский государственный \\ университет \\ Ivbykova@yandex.ru
}

Аннотация: Настоящая статья посвящена рассмотрению особенностей метафорического моделирования концепта брексит в британском, немецком и российском политическом дискурсе. Материалом исследования послужили статьи с использованием метафор из британских, немецких и российских СМИ, посвященные теме выхода Великобритании из Европейского союза. Задачами исследования являются выявление наиболее частотных метафорических моделей, проведение подробного анализа примеров с последующим приведением выводов относительно общего характера каждой метафорической модели.

Ключевые слова: брексит, СМИ, метафора, метафорическая модель, концепт, коннотация.
$\mathrm{M}$ етафора чрезвычайно часто встречается во всех сферах деятельности современного человека и почти во всех видах коммуникации. С помощью метафоры автор обращает внимание читателя или слушателя на определенный признак описываемого явления. Благодаря фигуральности она сглаживает резкие и резонансные высказывания о спорных проблемах, снижая ответственность говорящего и позволяя ему не выражать своего мнения напрямую. В коммуникативной деятельности метафора - важное средство воздействия на адресата [2].

В классической риторике метафора рассматривается как отклонение от нормы - переном одного предмета на другой, и используется такой перенос для компенсации отсутствия в лексической системе языка слова для обозначения того или иного понятия (лексическая лакуна). Другая функция метафоры - «украшение» речи. Метафора - вид тропа, основанный на перенесении свойств одного предмета (лица, явления) на другой по принципу их сходства в каком-либо отношении - по форме, цвету, ценности, функции и т. д., например, ножка стула, золотая голова, река спит [4].

Для лингвистической науки конца XX века особенно значимыми оказались представления о концептуальной метафоре (метафорической модели) как о средстве познания и объяснения действительности, т. к. она базируется на установлении ассоциативных связей, сходств и различий между явлениями и создает на этой основе новые личностные смыслы, которые представляют субъективное отношение индивида к миру, его трактовку определенного фрагмента действительности [1].

В отличие от классической метафоры, представляющей собой средство художественной выразительности, в когнитивной науке она понимается как важнейшая операция над понятиями, а также способ структурирования понятийной системы. Мы познаем неизвестное через известное, абстрактное - через конкретное, то 
есть знания переносятся из одной содержательной области в другую, а метафора рассматривается как важная ментальная операция, связанная с мышлением [3].

Метафора позволяет нам осмыслить абстрактные по природе, неструктурируемые предметы. Согласно теории концептуальной метафоры в понятийной системе человеческого разума заложены метафорические модели, это своего рода схемы, по которым человек думает и действует. В трудах современных лингвистов термин «метафорическая модель» понимается по-разному.

Согласно определению А.П. Чудинова, метафорическая модель - существующее в сознании носителей языка типовое соотношение семантики первичных и вторичных значений, являющееся образцом для возникновения новых вторичных значений [10].

Существует огромное количество метафорических моделей, которые помогают выразить одно понятие через другое. Изучение этих моделей, в свою очередь, способствует более глубокому пониманию мировоззрения и поведения, а также особенностей восприятия действительности разных народов.

Таким образом, концептуальная метафора в настоящее время активно исследуется, она являет собой инструмент мышления и познания, отражает культурные особенности разных народов, так как ее основой является национально-культурное видение мира.

Метафора находит достаточно широкое использование в средствах массовой информации, которые являются главным зеркалом всех мировых событий. Она не только помогает создать яркую и целостную картину происходящего, но и реализует одну из основных функций СМИ - воздействующую.

Язык СМИ в силу своей тесной связи с процессами, происходящими в обществе, представляет на сегодняшний день большой интерес для исследователей-лингвистов, политологов, психологов. В научной литературе постоянно подчеркивается роль средств массовой информации в функционировании современного общества. Тезис о «четвертой власти» все чаще становится предметом пристального внимания и обсуждения в сообществе. Грамотное использование богатейших средств речевой выразительности языка, среди которых метафора занимает ключевое место, помогает решить любые коммуникативные задачи, которые ставят перед собой современные публицисты. Создаваемый авторами газетных статей при помощи метафоры яркий зримый образ суггестивно влияет на восприятие информации под определенным углом зрения [9].

Предметом нашего исследования является метафо- рическое моделирование в политическом дискурсе. Материалом нашего исследования послужили статьи с использованием метафор из британских, немецких и российских СМИ, посвященные теме выхода Великобритании из Европейского союза, опубликованные в период с июня 2016 г. по декабрь 2019 г. В ходе исследования было отобрано и проанализировано 573 примера.

В российской прессе одной из наиболее распространенных метафорических моделей при освещении процесса выхода Великобритании из Евросоюза является «Брексит - Театр», вербализованная главным образом в лексике, описывающей части театральной постановки, либо обозначающей жанровую принадлежность театрального произведения. Рассмотрим некоторые примеры.

«До развязки драмы под названием брексит, начавшейся в июне 2016 года, остаётся совсем мало времени - 29 марта 2019 года Великобритания официально покинет Евросоюз. Один из ключевых эпизодов будет разыгран сегодня, 15 января <...>» («Парламентская газета», 15.01.2019). Согласно толковому словарю русского языка С. И. Ожегова основным значением лексемы «драма» является «род литературных произведений, написанных в диалогической форме и предназначенных для исполнения актерами на сцене». Поскольку в статье речь идет не о театральном представлении, а о событиях на политической арене, мы можем сделать вывод, что здесь слово «драма» является метафорой. В силу того, что процедура брексита зачастую сопровождается противоречивыми, а порой - и нелепыми с точки зрения некоторых сторонних наблюдателей, действиями со стороны британского правительства, автор статьи явственно подчеркивает, что в последнее время политический процесс по данному вопросу походит скорее на театральную драматическую постановку. Автор продолжает развивать данную метафору, используя выражение «один из ключевых эпизодов будет разыгран», где при помощи метафоры «разыграть» вновь проводится сравнение брексита с игрой, постановкой, а посредством метафоры «эпизод» данный политический процесс сравнивается с многосерийным фильмом или многоактовой театральной постановкой, что указывает на его затяжной характер. Данные метафоры, очевидно, обладают отрицательной коннотацией.

«Мыльная опера под названием «брекзит» подходит к логическому кончу» («Российская газета», 22.11.2018). Согласно энциклопедическому словарю крылатых слов и выражений В. Серова словосочетание «мыльная опера - мелодраматический сериал с невысокими художественными достоинствами; также о поведении кого-либо, напоминающем поведение персонажей из телевизионных многосерийных мелодрам». Поскольку изначально главной целью мыльных опер, которые впер- 
вые появились в США в конце 30-х годов, была реклама всякого рода моющих и чистящих средств (отсюда и название - «мыльная»), то актерское исполнение и общее качество постановки в таких телепрограммах зачастую отодвигалось на второй план и не отличалось высоким уровнем. Таким образом, использование в данном примере метафоры «мыльная опера» вновь указывает на сильную затянутость брексита, а также на недостаточный профессионализм и излишнюю драматичность в поведении сторон процесса. Как видно из контекста, данная метафора носит очевидный отрицательный оттенок.

Таким образом, ключевыми лексемами метафорической модели «Брексит - Театр» в российской прессе являются «драма», «эпизод», «разыграть», «мыльная опеpa».

Сфера-источник «Развод» также находит широкое применение среди отечественных журналистов. Так, с помощью метафор модели «Брексит - Развод» зачастую осуществляется сравнение брексита с типичным семейным раздором. Рассмотрим некоторые примеры.

«Мы, честно говоря, ожидали семейного скандальчика с битьем посуды, угрозами «уйти к маме» и финальным примирением с перспективой покупки «шубки» дополнительных квот и бонусов» («Завтра», 1.07.2016). Данный фрагмент наглядно отражает изначальное отношение большей части мировой общественности к идее брексита. Так, метафора «семейный скандальчик с битьем посуды, угрозы уйти к маме» позволяет описать политический процесс как беспочвенную женскую истерику со стороны Великобритании. Данный образ становится еще более выразительным благодаря уменьшительно-ласкательному суффиксу чик в лексеме «скандальчик», что, вместе с усилением эмоционально-оценочного компонента лексемы, характеризует брексит как нечто несущественное и неприметное, нестоящее пристального внимания и обсуждения. Кроме того, данный образ подкрепляется словосочетанием «угрозы уйти к маме»: вероятно, в данном контексте подразумевается отлучение Британии от «совместной жизни» с Евросоюзом и ее возврату к отдельному и независимому существованию; однако лексема «угроза» подчеркивает несерьезность намерений, указывает на то, что реальных попыток выхода Великобритании из Евросоюза предпринято не будет. Наконец, с помощью метафоры «финальное примирение с перспективой покупки шубки» автор мастерски изображает предполагаемый исход типичного семейного скандала: здесь Великобритания рисуется как меркантильная супруга, требующая извинений в виде материальных подарков («шубы») за скандал, который сама и устроила. Несмотря на то, что примирение - положительный исход любой ссоры, в данном контексте прослеживается явная ирония, которая сохраняет эмоциональный фон пред- ложения отрицательным. Из вышесказанного следует, что метафоры в данном примере, выступая в качестве стереотипизированной модели поведения супруги во время ссоры, свидетельствуют о том, что первоначально инициатива брексита воспринималась как не более чем незначительная показная демонстрация недовольства со стороны британского правительства, которое, якобы, стремилось посредством заявлений о выходе из ЕС получить дополнительные привилегии в «семействе» Евросоюз. Все метафоры в данном примере содержат ярко выраженную отрицательную коннотацию.

«На нем [экстренном саммите лидеров странчленов EC] был официально оформлен развод между Лондоном и Брюсселем и запущена прочедура «брекзита» - официального выхода Великобритании из состава EC» («Российская газета», 25.11.2018). В данном примере мы выделяем метафору «был официально оформлен развод». В статье сообщается о наконец утвержденном после длительных переговоров договоре о брексите, который ознаменовал скорую отмену статуса Великобритании как члена Евросоюза. Как и при разрушении семьи в реальной жизни, выход Британии из ЕС воспринимается здесь как трагичное, печальное событие. Более того, подобно тому, как любой процесс расторжения брака между людьми сопровождается разделом имущества и назначением иных экономических обязательств супругов, брексит также влечет значительные негативные экономические последствия для сторон договора. Таким образом, в данном примере брексит изображается как нежелательный и катастрофический процесс, недостатки которого значительно превышают преимущества для Великобритании и ЕС. Метафора содержит очевидную отрицательную коннотацию.

Таким образом, ключевыми лексемами метафорической модели «Брексит - Развод» в российской прессе являются «скандальчик», «битье посуды», «угрозы», «примирение», «подарок», «развод».

Не менее распространенной сферой-источником метафорической экспансии при описании процесса брексита в российских СМИ является медицина. В частности, особое место здесь занимает модель «Брексит Болезнь», метафоры которой характеризуют брексит как явление болезненное, нездоровое. Обратимся к примерам.

«Брекзит <...> - тот самый спор, «головная боль» правительства Терезы Мэй. <...> Инцидент в Солсбери - это трюк, «дохлый кот», швыряя которого в информачионное поле, британские власти расчитывают, как минимум, переключить внимание собственных граждан с неприятных для себя тем» («Комсомольская правда», 4.03.19). Довольно популярной морбиальной метафорой, прочно вошедший в узус русского языка, является 
выражение «головная боль», которое трактуется Большим словарем русских поговорок как «разг. Сложная проблема, предмет переживаний, забот, волнений» [5]. Несмотря на то, что статья, из которой взят настоящий пример, посвящена сенсационному и скандальному делу об отравлении Сергея Скрипаля и его дочери Юлии в марте 2018 года, автор напрямую связывает подозрительные и противоречивые действия британского правительства в отношении данного инцидента с ее неудачной политикой в проведении брексита. На момент публикации статьи переговоры по вопросу выхода Великобритании из ЕС длились уже без малого 3 года, и за этот период британский парламент успел продемонстрировать свою неспособность предложить четкие и адекватные условия, которые регулировали бы столь сложный с точки зрения политики и экономики процесс. По мнению автора статьи, единственным эффективным способом для Британии сместить центр внимания мировой общественности с брексита, уже ставшим предметом всеобщих насмешек, была некая диверсия, которой как раз кстати оказалось дело Скрипалей. Из этого следует вывод, что брексит изображается здесь как действующий на нервы болезненный симптом, который в силу своего затяжного характера приносит дискомфорт, и от которого хочется поскорее избавиться. Коннотация данной метафорической единицы является отрицательной.

«Референдум нужен страдающей политической диареей «англичанке» <...>» («Завтра», 24.07.18). В связи с тем, что в сознании большинства людей брексит ассоциируется и отождествляется с идейным вдохновителем и негласным лицом данного процесса, Терезой Мэй, весьма часто именно она становится мишенью журналистских метафор, которые описывают политическую деятельность данной личности, ее имидж, а также личные качества. В данном примере мы находим лексему «англичанка» с явным пренебрежительным оттенком, которая и является отсылкой к Терезе Мэй. Будучи известной своими частыми непоследовательными и неуместными решениями и заявлениями, экс-премьер-министр Соединенного Королевства не раз заводила очередное заседание ЕС по вопросу брексита в тупик, заставляя постоянно переносить дату принятия окончательного решения. Именно такие действия со стороны Терезы Мэй автор данной статьи язвительно называет «политической диареей» - бесконтрольными и порывистыми политическими «выпадами». Данная метафора обладает резко отрицательной коннотацией.

Необходимо отметить, что благодаря комбинации двух языковых единиц с отрицательной коннотацией (пренебрежительная лексема «англичанка» и метафора «страдающая политической диареей») данное предложение отличается чрезвычайно высоким уровнем эмфатизации.
Таким образом, ключевыми лексемами метафорической модели «Брексит - Болезнь» в российской прессе являются «головная боль», «страдать», «диарея».

Далее перейдем к рассмотрению метафорических моделей в немецких печатных СМИ. Как и в российской прессе, в немецкой одной из наиболее распространенных моделей является „Brexit - Theater“.

„Die anderen wundern sich nur noch, dass das absurde Theater im britischen Parlament immer noch einen Akt der Steigerung bereit hat..." («Другие же просто удивляются, что у этого театра абсурда, который происходит сейчас в британском парламенте, все еще предстоит акт подъема...») (газета „Kurier", 29.03.2019). Как видно из примера, немецкая пресса также воспринимает дело о выходе Великобритании как театральное представление, более того характеризует его как «абсурдный». В частности, в статье идет речь о противоречивости действий британского правительства: в данный период британский парламент неоднократно подчеркивал желание осуществления брексита, однако при этом все-же отклонял соглашение о выходе страны из ЕС, за которое так боролась Тереза Мэй, - поэтому в итоге она подала в отставку, чтобы нежелательный, но официальный выход был, наконец, совершен. Именно поэтому действия со стороны Великобритании описываются здесь метафорой «театр абсурда». Кроме того, автор статьи использует метафору „Akt der Steigerung“, благодаря чему вновь подчеркивается затянутость, «многоактовость» брексита. Так, автор указывает на то, что вопрос о выходе Великобритании из ЕС до сих пор не достиг кульминации даже спустя 2 года с его начала. Коннотация рассматриваемых нами в этом примере единиц отрицательная.

„Das wahre Brexit-Drama steht jetzt bevor" («Tenepь предстоит настоящая драма «брексит»») (газета „Die Welt", 8.12.2017). В данном примере мы выделяем метафору „Brexit-Drama“, которая вновь указывает на схожесть событий, связанных с брекситом, и драматической постановки. Данная статья была опубликована в период, когда Лондону и Брюсселю удалось получить первые реальные результаты переговоров касательно брексита, для чего однако, Терезе Мэй пришлось пойти на большое количество уступок, которые могли бы отрицательно повлиять на общее положение Великобритании в случае выходя страны из ЕС на этих условиях. Таким образом, автор статьи подчеркивает, насколько драматичным исходом оборачивается Великобритании их собственная инициатива по брекситу. Коннотация данной метафоры, очевидно, является отрицательной.

Итак, в немецкой прессе ключевыми лексемами метафорической модели „Brexit - Theater“ являются „absurd“, "Theater" , „Akt", ,Drama". 
Среди наиболее распространенных в немецкой прессе метафорических моделей, из которых журналисты черпают различные средства описания процедуры брексита, мы также выделяем модель „Brexit - Erkrankung“. В отличие от аналогичной метафорической модели в российской прессе («Брексит - Болезнь»), немецкие метафоры данной модели характеризуются ярко выраженной резкостью и язвительностью: здесь брексит - не просто недуг, а зачастую мучительная и невыносимая болезнь, влекущая за собой тяжелые «осложнения». Обратимся к примерам.

„Der fiebrige Zustand der britischen Politik steuert auf einen neuen akuten Anfall Ende kommender Woche zu <...>" («В конце следующей недели лихорадочное состояние британской политики закончится очередным острым приступом») (газета "Neue Züricher Zeitung", 1.07.2018). Согласно толковому словарю немецкого языка Duden главным значением прилагательного „fiebrig" является «больной лихорадкой; страдающий лихорадкой». Поскольку в данном примере речь идет не о человеке и биологических процессах в его организме, а о состоянии политики, то данная лексема используется здесь в переносном, метафорическом смысле, а именно: «в ожидании чего-то; в состоянии ажиотажа, волнения». Данная метафора довольно точно и ярко передает настроения в британском правительстве по состоянию на июль 2018 года, когда все внимание не только британской и европейской, но и также мировой общественности было приковано к процедуре брексита. Тогда еще действующему премьер-министру Соединенного Королевства, Терезе Мэй, и ее кабинету не удалось принять ряд сверхважных решений для благоприятного выхода Великобритании из Евросоюза («мягкий брексит») даже спустя 15 месяцев с момента начала процедуры брексита, поскольку выдвигаемые Терезой Мэй предложения оказывались, в конечном счете, невыгодными для EC, а иногда - вовсе невыполнимыми. Разумеется, проведение непродуктивных переговоров на протяжении столь долгого периода времени заставило британское правительство постоянно находиться в напряженном, судорожном состоянии, что и отражено в данной метафоре. Далее, используя метафору „ein akuter Anfall", автор статьи завершает созданный образ и изображает своего рода кульминацию, наивысшую точку лихорадочного состояния - «острый приступ», подразумевая надвигающийся дипломатический провал Лондона. Кроме того, посредством использования в данной метафоре эпитета „nеu“ («новый, очередной») автор подчеркивает многократность таких провалов со стороны Великобритании. Рассматриваемые в данном примере метафоры носят явную отрицательную коннотацию.

„Am Ende war es die Wahl zwischen Pest und Cholera und ein Ergebnis, mit dem niemand recht zufrieden sein kann" («B конце концов, это был выбор между чумой и холерой - результат, которым никто не может быть полностью доволен») (газета „Frankfurter Rundschau", 11.04.2019). Выражение "die Wahl zwischen Pest und Cholera" является довольно распространенным и широкоупотребительным фразеологизмом в немецком языке, который, как и большинство идиом, базируются на метафорическом переносе. Толковый словарь устойчивых выражений Duden трактует данный фразеологизм как «выбор между двух зол, в [почти] безвыходной ситуации». В данном примере метафора как нельзя точно описывает очередную неудачу в принятии решении по поводу выхода Великобритании из ЕС: в силу неспособности британского правительства выдвинуть благоприятные условия для брексита Европарламент вынужден постоянно откладывать дату его осуществления. Таким образом, и принятие условий Британии, и постоянные переносы срока брексита являются нежелательными исходами для Евросоюза, однако выбор между двумя альтернативами всегда оказывается неизбежным. Очевидно, что данная метафора носит отрицательную коннотацию.

Таким образом, в немецкой прессе метафорическая модель „Brexit - Erkrankung” представлена следующими ключевыми лексемами: „fiebrig”, „akuter Anfall”, „Pest”, „Cholera”.

Достаточно большое количество метафор при описании брексита в немецких печатных СМИ относятся к сфере-источнику «спорт». Вербализация модели „Brexit - Sport" происходит за счет лексем, обозначающих виды спорта, их правила, спортивный инвентарь и т.д. Далее проанализируем два показательных примера.

„May schlägt EU im Brexit-Tauziehen «verschiedene Optionen» vor" («Мэй предлагает EC «различные варианты» касательно соревнования по перетягиванию каната под названием "Брексит»») (газета "Stern", 07.02.2019). В данном примере мы выделяем лексему „Tauziehen“ («перетягивание каната»), которая очевидно используется здесь в переносном, метафорическом смысле. Как и в русском языке, в немецком данная спортивная метафора означает «борьбу двух одинаковых по силе, но противоположных по взглядам или интересам сторон по поводу какого-либо решения», а также «бесполезную суматоху или возню» [8]. Действительно, как уже упоминалось ранее, переговоры между британским правительством и Евросоюзом преимущественно сводились к разногласиям и бесконечным переносам даты осуществления брексита. Поскольку отказ от курса брексита означал бы для кабинета Терезы Мэй признание несостоятельности идеи, что в свою очередь привело бы к значительному подрыву авторитета Консервативной партии Британии, как в самой стране, так и за ее пределами, Лондон принимал все более отчаянные попытки по максимально возможному оттягиванию времени в надежде найти убедительные и вразумительные доводы 
в пользу брексита. Именно из-за малопродуктивной и, порой, алогичной деятельности сторонников брексита и резкого несогласия ЕС с выдвигаемыми британским парламентом условиями проведения процедуры данная ситуация ассоциируется у общественности с бесцельной полемикой - «перебрасыванием мяча» или «перетягиванием каната». Как видно из примера, данная метафора имеет отрицательную коннотацию.

"Theresa May macht sich fürs Penaltyschießen bereit" («Тереза Мэй готовится к серии пенальти») (газеma "Neue Züricher Zeitung", 1.07.2018). Не менее показательным примером является спортивная метафора „Penaltyschießen“. В немецком языке сложное слово „Penaltyschießen" (от англ. "penalty" - «штрафной удар или бросок; пенальти» и нем. „das Schießen“ - «стрельба, запуск») используется для обозначения одиннадцатиметрового штрафного удара в футболе. На момент публикации статьи в кабинете Терезы Мэй назревали нешуточные разногласия по поводу позиции Лондона в переговорах с Брюсселем: британский парламент ожидал раскол. Кроме того, с каждыми неудачными переговорами отношение ЕС к бреситу необратимо и стремительно обострялось. Поскольку Тереза Мэй оказалась в достаточно затруднительном положении, буквально «между двух огней», общественность начала задаваться вполне логичным вопросом: «Что же Тереза Мэй собирается делать дальше, чтобы урегулировать сложившуюся ситуацию?». Таким образом, в данном примере автору статьи удается мастерски изобразить Терезу Мэй в качестве голкипера, которому предстоит отразить внушительное количество пенальти, силу которых трудно предсказать. Метафора носит ироничный характер, а значит, обладает отрицательной коннотацией.

Таким образом, в немецкой прессе метафорическая модель „Brexit - Sport” представлена следующими ключевыми лексемами: „Tauziehen”, „Penaltyschiessen”.

В британской прессе наиболее распространенной метафорической моделью оказалась "Brexit - Food", вербализованная в лексемах, связанных с пищей, процессом ее приготовления, а также со сферой общественного питания. Рассмотрим несколько примеров.

"If you order a meal which never comes, you can ask for something else. If the meal is not what you ordered, you send it back. If you know it is going to make you ill, you don't eat it. $\langle\ldots\rangle$ it is clear they don't know how to make this dish and it doesn't exist. That is Brexit" ("Если вы заказали блюдо, а вам его никак не выносят, вы можете попросить что-нибудь другое. Если вам принесли не то, что вы заказывали, - попросите унести заказ. Если вы знаете, что вам станет плохо от этого блюда, - не ешьте eго. <...> совершенно ясно, что никто понятия не имеет, как готовить это блюдо, и что оно не существу- ет. Имя этому блюду - Брексит») (газета "Independent", 24.09.2018).

"<...> Britain did not want to have its cake and eat it; it just did not agree with the EU what the recipe for the cake should be" («Британия отказалась взять и съесть предназначенный ей пирог. Ей просто не удалось договориться с $Е С$ насчет его рецепта») (информационный портал "BВC News", 28.07.2017).

В двух данных фрагментах мы наблюдаем развернутые метафоры, сферой-источником которых является пища. Так, с помощью сравнения условий соглашения с блюдом ("meal"), в первом примере происходит метафорический перенос с порядка принятия решений на переговорах на действия, предпринимаемые любым человеком во время похода в кафе или ресторан: если условия соглашения не осуществимы ("never come") - необходимо их пересмотреть ("ask for something else"); если хотя бы одна сторона не согласна с условиями соглашения ("is not what you ordered") - их нужно отклонить ("send it back"); если условия соглашения могут принести вред сторонам ("make you ill") - их нельзя принимать ("don't eat it"). Метафоры “order a meal" и "eat it", в отличие от остальных метафор данного фрагмента, не содержат эмоционально-оценочную коннотацию.

Во втором примере мы сталкиваемся с метафорой "cake", под которой очевидно подразумевается соглашение о брексите, и метафорой "recipe", которая означает условия данного соглашения. Все метафоры данного фрагмента не содержат эмоционально-оценочную коннотацию.

Таким образом, как и в некоторых предыдущих примерах, здесь также затрагивается тема непродуктивности переговоров между Лондоном и Брюсселем, а именно - неспособностью сторон прийти к соглашению.

Итак, в британской прессе метафорическая модель "Brexit - Food" представлена следующими ключевыми лексемами: "order", "meal", "send back", "dish that never comes", "ask for something else", "cake", "eat", "recipe".

Для британской прессы также характерно достаточно частое обращение к такой сфере-источнику метафорической экспансии как "Theatre". Здесь, как и в российских и немецких печатных СМИ, события брексита зачастую отождествляются с драматической постановкой. Перейдем к рассмотрению примеров.

"It is instead a long kabuki drama in which politicians, not least Eurosceptics, advocate policies they would never actually implement" («Hапротив, это длинная драма кабуки, где политики, а также евроскептики, защищают политику, которую никогда бы сами не осуществили») (газета 
"Financial Times", 8.04.2016). При анализе примеров из британской прессы мы установили, что отношение самих британцев к брекситу носит явный негативный характер. В данном примере мы выделяем метафору „kabuki drama“. Кабуки - это классический театр в Японии, сочетающий драматические, танцевальные и музыкальные элементы, а его неотъемлемыми атрибутами являются грим и театральные маски. Средняя длительность выступления в таком театре является относительно высокой 5-6 часов, что значительно дольше продолжительности более типичных театральных представлений. Так, сравнивания брексит с драматическим кабуки автор ярко и едко передает свое видение данного процесса, который представляет собой бесконечный спектакль лицемерия, где все актеры скрывают свои лица за гримом или масками, и прикладывают все усилия, чтобы сделать представление как можно более драматичным, интересным для зрителя. Очевидно, что коннотация данной метафоры является отрицательной.

"The Brexit farce is about to turn to tragedy" ("Фapc "Брексит» вот-вот превратится в трагедию») (газета "Financial Times", 22.03.2019). В данном примере мы выделяем метафоры "farce" и "tragedy". Согласно толковому словарю Collins Concise English Dictionary, лексема "farce" имеет значения «юмористическая пьеса, основанная на невероятных ситуациях; жанр комедии, представленный произведениями такого рода; нелепая ситуация или действие». Таким образом, автор данной статьи не только называет брексит нелепым театральным представлением, но и как бы «предрекает» скорый печальный исход для британского правительства. Кроме того, на основе метафорического сравнения брексита с фарсом и трагедией в данном случае строится такая риторическая фигура как антитеза. Как и во всех предыдущих примеров, коннотация метафор в данном примере является отрицательной.

Таким образом, в британской прессе метафорическая модель "Brexit - Theatre" представлена следующими ключевыми лексемами: "kabuki", "drama", "farce", "tragedy".

Как и в российской и немецкой прессе, среди британских журналистов особой популярностью для сообщения актуальных новостей, связанных с процедурой брексита, пользуется метафорическая модель "Brexit - Disease", которая, однако, имеет некоторые особенности. В частности, метафоры данной модели зачастую используются для описания главного деятеля в вопросе брексита в правительстве Великобритании - Терезы Мэй. Кроме того, лексемы, в которых вербализуется модель, в основном обозначают состояние человеческого организма в экстремальных ситуациях, предсмертное состояние человека или смерть. Рассмотрим несколько примеров.
"Many believe that hearing is the last sense to be lost. If true, Theresa May must have been a goner for some time now. She hasn't heard a word anyone has said to her for month" («Многие считают, что слух - последнее чувство, которое теряет человек. Если это правда, Тереза Мэй, должно быть, уже давно нежилец. Она не слышала ни одного слова, сказанного ей в течение нескольких месячев») (газета "The Guardian", 22.05.2019). Под конец своей политической деятельности в качестве премьер-министра Великобритании Тереза Мэй особенно часто подвергалась критике за бескомпромиссность и нежелание прислушиваться к каким-либо советам и замечаниям по поводу ее стратегии в осуществлении процедуры брексита. Не обращая внимания на внушительное количество явных пробелов в линии поведения на международной арене, Тереза Мэй отчаянно пыталась «удержаться на плаву», не погубить свою репутацию, предпринимая при этом все более нелепые действия на переговорах с Европарламентом. А на вполне уместные и требующие конкретных ответов вопросы своих оппонентов премьер-министр все чаще ссылалась на уже ставшую клишированной фразу «Брексит значит Брексит», тем самым избегая каких-либо разъяснений. Так, в данном примере автор статьи в довольно ироничной и слегка резкой форме подчеркивает столь странное поведение премьер-министра, полагая, что вероятно она лишилась слуха, из чего автор делает вывод, что Тереза Мэй - и вовсе мертвец. Следовательно, здесь премьерминистр Великобритании изображается как зомби: способна ходить, но совершенно лишена каких-либо чувств восприятия. Коннотация данной метафоры явно отрицательная.

"Her [Theresa May's] pain threshold must be off the scale. Each day a greater torment than the last" ("Должно быть, у нее [Терезы Мэй] запредельный болевой порог. С каждым днем ее мучают все больше») (газета "The Guardian", 22.05.2019). В данном примере морбиальная метафора "pain threshold" используется как средство насмешки над Терезой Мэй. В частности, здесь автор статьи высмеивает необъяснимое поведение премьер-министра Великобритании, напоминающее ситуацию из предыдущего примера: несмотря на катастрофическое положение дел по вопросу о брексите, несмотря на бесконечные нападки и критику со стороны не только своих оппонентов, но и сторонников, Тереза Мэй старательно и упорно делает вид, будто все в порядке, и продолжает заявлять, что она безгранично любит свою работу. Автор иронично подчеркивает, что не представляет, насколько невыносимой должна быть работа, чтобы не понравиться Терезе Мэй. Данная метафора содержит отрицательную коннотацию.

Таким образом, в британской прессе метафорическая модель "Brexit - Disease" представлена следующими ключевыми лексемами: "hearing", "sense", "lose", "goner", "pain". 
На основе анализа примеров мы можем сделать вывод, что видение брексита в СМИ России, Германии и Великобритании во многом схоже: во-первых, большинство рассмотренных нами метафор содержат отрицательную коннотацию, что говорит о негативном отношении к брекситу в сознании россиян, немцев и британцев; во-вторых, для описания процесса брексита в прессе трех данных стран наиболее частотно используется схожий набор метафорических моделей: «Брексит - Театр» и «Брексит - Болезнь».

ЛИТЕРАТУРА

1. Арутюнова, Н.Д. Метафора и дискурс: предисловие [Текст] / Н.Д. Арутюнова // Теория метафоры. - М.: Прогресс, 1990. - с. 5-32.

2. Кухаренко, В.А., Гальперин, И.Р., Арнольд, И.В. Словарь терминов по стилистике английского языка / сост. Куракин А.В., 3-я ред., испр. и доп. 2004. - 240 с

3. Лакофф Дж., Джонсон М. Метафоры, которыми мы живем : пер. с англ. / под ред. и с предисл. А.Н. Баранова. - М. : Едиториал УРСС, 2004. - 256 с.

4. Мещеряков, В.П. Основы литературоведения: учебное пособие для студентов педагогических вузов / В.П. Мещеряков, А.С. Козлов и др. - М.: Дрофа, 2003. $-416 C$.

5. Мокиенко В.М., Никитина Т.Г. Большой словарь русских поговорок. - М.: ЗАО «0ЛМА Медиа Групп», 2007. - 784 с.

6. Ожегов С. И. Толковый словарь русского языка: 80000 слов и фразеологических выражений / С.И. Ожегов, Н.Ю. Шведова; Российская академия наук. Институт русского языка им. Виноградова. - 4-е изд., дополненное. - М.: 000 «ИТИ ТЕХНОЛОГИИ», 2003. - 944 с.

7. Словарь Duden [Электронный ресурс] Режим доступа: https://www.duden.de/

8. Словарь Digitales Wörterbuch der deutschen Sprache [Электронный ресурс] Режим доступа: https://www.dwds.de/

9. Таджибова А.Н. - Мир метафоры и мир метафоры в массмедийном дискурсе // Litera. - 2016. - № 2. - C. 35 - 44. D0I: 10.7256/2409-8698.2016.2.19135 URL: https://nbpublish.com/library_read_article.php?id=19135

10. Чудинов, А.П. Россия в метафорическом зеркале: когнитивное исследование политической метафоры / А.П. Чудинов. - Екатеринбург: Русская речь, 2001. -237 c.

11. Энциклопедический словарь крылатых слов и выражений: Более 4000 статей / [авт.-сост. В. Серов]. - 2-е изд. - М. : Локид-Пресс, 2005.- 880 с.

12. The Concise 0xford Dictionary of English Etymology / ed. by T.F. Hoad . - Oxford : Oxford University Press, 2003. - XIV, [2], 552 p.

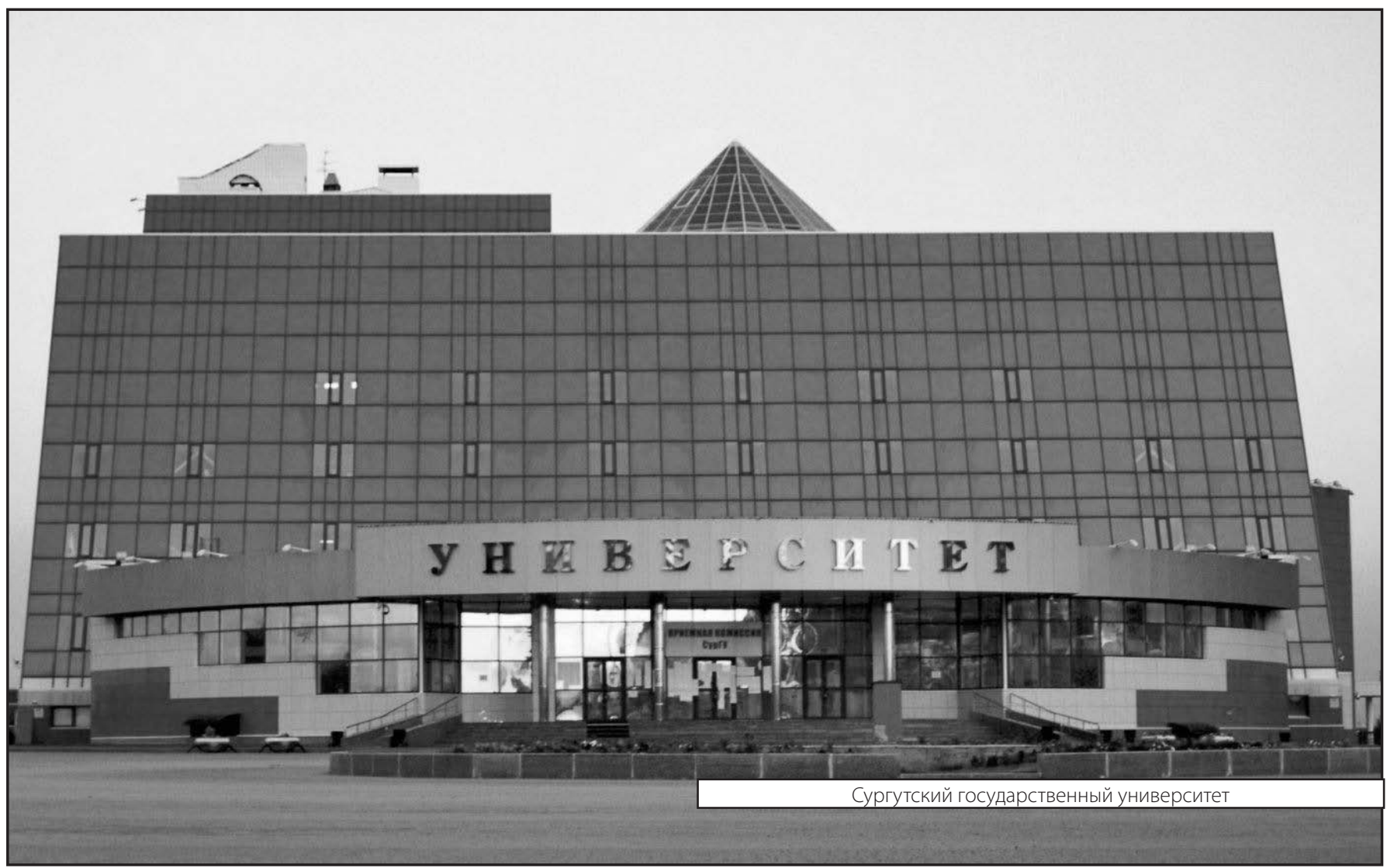

